\title{
STRATEGI PENGEMBANGAN PEMASARAN MAKANAN KHAS BENGKULU PADA SENTRA OLEH-OLEH ANGGUT KOTA BENGKULU: APLIKASI AHP DAN SWOT
}

\author{
MARKETING DEVELOPMENT STRATEGY OF BENGKULU \\ TRADITIONAL FOOD IN SOUVENIR SHOP AREAS OF ANGGUT \\ BENGKULU CITY : APPLICATION OF AHP AND SWOT
}

\author{
Chresy Novralina Hutagalung, Nusril, dan Teguh Adiprasetyo \\ Jurusan Sosial Ekonomi Pertanian Fakultas Pertanian Universitas Bengkulu
}

\begin{abstract}
The aim for this research is to know the marketing development strategic of traditional meal in Centra traditional food Anggut Bengkulu City using Analytical Hierarchy Process (AHP) method dan SWOT analysis. The samples are Cita Rasa, Kueku Yovita and Arzel. To find the priority factor from each marketing mix used Analytical Hierarchy Process (AHP) method. This research showed that the priority factor from product mix is the hygiene product $(0,1222)$. The priority factor from price mix is the value for money $(0,2025)$. The priority factor from promotion mix is positioning the local product $(0,1539)$. The priority factor from place mix is market location position $(0,1841)$. The internal and external environment is used in SWOT analysis matriks. The Cita Rasa marketing development strategics are giving incentive price for consumers, market expansion, keep and maintain quality, taste and locallity product, and decorate the layout on the attractive display. The Kueku Yovita marketing development strategics are increase the promotion and advertising, giving incentive price for consumer, market expansion, and decorate the layout on the attractive display. The Arzel marketing development strategics are increase the promotion and advertising, giving incentive price for consumer, market expansion, increase the quality, hygiene and taste product, and decorate the layout on the attractive display.
\end{abstract}

Keyword : marketing development strategic, Analytical Hierarchy Process (AHP), SWOT

\section{PENDAHULUAN}

Sektor UKM telah dipromosikan dan dijadikan sebagai agenda pembangunan ekonomi Indonesia. Ketangguhan UKM terbukti pada saat terjadi krisis ekonomi tahun 1998. Selama 1997-2006, jumlah perusahaan berskala UKM 
mencapai 99\% dari keseluruhan unit usaha di Indonesia. Pemberdayaan UKM menjadi sangat strategis karena potensinya yang besar dalam menggerakkan kegiatan ekonomi masyarakat dan sekaligus menjadi tumpuan sumber pendapatan sebagian msyarakat Indonesia. Perkembangan jumlah UKM periode 2006-2007 mengalami peningkatan sebesar 2,18\% dari 48.779 .151 menjadi 49.840.489 unit. Salah satu unit usaha UKM tersebut adalah industri pengolahan dengan persentase $6,48 \%$. (Afiah, 2009)

Salah satu kawasan di Kota Bengkulu yang mencakup banyak usaha kecil dan menengah dan melakukan kegiatan pengolahan adalah Anggut. Dalam menjalankan usaha kecil khususnya diperlukan adanya pengembangan melalui strategi pemasarannya. Penelitian ini dilakukan pada tiga unit usaha yang dipilih berdasarkan jumlah omset yang dimiliki dari yang paling besar, menengah dan paling kecil, yaitu Cita Rasa, Kueku Yovita dan Arzel.

Strategi pengembangan pemasaran makanan khas Bengkulu ditentukan dengan empat alternatif strategi pengembangan yaitu strategi S-O, W-O, S-T dan W-T. Menurut Rangkuti (1998) dalam Marimin (2004), analisis SWOT adalah suatu cara untuk mengidentifikasikan berbagai faktor secara sistematis dalam rangka merumuskan strategi perusahaan.

Pemasaran tidak terlepas dari empat bauran pemasaran yang sering dikenal dengan 4P, yaitu produk, harga, promosi dan tempat. Dalam menjalankan usaha, penting bagi pelaku usaha untuk memperhatikan keempat hal ini dan menentukan faktor yang paling diprioritaskan dari masing-masing bauran pemasaran sebagai strategi pengembangan pemasarannya. Untuk mengetahuinya digunakan metode AHP (Analytical Hierarchy Process). Metode AHP digunakan untuk pengambilan keputusan dari berbagai keputusan yang ada (Marimin, 2004).

Berdasarkan latar belakang di atas, penelitian ini bertujuan (a) menemukenali lingkungan internal (kekuatan dan kelemahan) serta lingkungan eksternal (peluang dan ancaman), mengetahui faktor bauran pemasaran yang paling diprioritaskan sebagai strategi pengembangan pemasaran makanan khas, dan menyusun strategi pengembangan pemasaran makanan khas yang tepat dan sesuai dengan faktor internal dan eksternal di Sentra Oleh-oleh Cita Rasa, Kueku Yovita, dan Arzel.

\section{METODE PENELITIAN}

Penelitian dilakukan di Sentra Oleh-oleh Anggut Kota Bengkulu yang bertempat di Kecamatan Ratu Samban Kota Bengkulu. Pengambilan sampel dilakukan berdasarkan jumlah omset yang dimiliki, yaitu sampel dengan jumlah omset yang paling besar, menengah dan paling kecil. Sampel dalam penelitian ini adalah Cita Rasa, Kueku Yovita dan Arzel.

Responden dalam penelitian ini dibagi ke dalam dua kategori, yaitu responden untuk metode AHP dan analisis SWOT. Responden untuk metode AHP terdiri dari delapan orang pakar yang berasal dari akademis, pelaku usaha 
dan Dinas UKM dan Koperasi Kota Bengkulu. Responden untuk analisis SWOT adalah 45 orang. Pengambilan data responden analisis SWOT dilakukan dengan menggunakan metode Cluster Sampling (Nazir, 1987). Dari analisis SWOT ditemukan strategi pengembangan pemasaran makanan khas dengan menggunakan matriks SWOT.

\section{HASIL DAN PEMBAHASAN}

\section{Karakteristik Responden}

Karakteristik responden menggambarkan bagaimana keadaan responden makanan khas Bengkulu di Sentra Oleh-oleh Anggut Kota Bengkulu, diantaranya umur, tingkat pendidikan, pekerjaan dan penghasilan.

Persentase tertinggi untuk karakteristik umur dari keseluruhan responden adalah 33,33\% dengan tingkat umur 18-27 tahun. Persentase umur yang terendah dari keseluruhan responden adalah 13,33\% dengan tingkat umur besar sama dengan 48 tahun. Berdasarkan persentase, dapat dilihat bahwa responden makanan khas umumnya tergolong dewasa.

Berdasarkan tingkat pendidikan, dari keseluruhan responden $48,89 \%$ yaitu sebanyak 22 orang dengan tingkat pendidikan S1. Tida ada satupun responden yang memiliki tingkat pendidikan di bawah SMP. Hal ini menunjukkan bahwa mayoritas responden makanan khas Bengkulu telah menyelesaikan pendidikan lebih dari 9 tahun. Lebih lanjut, terkait dengan jenis pekerjaan, 33,33\% responden memiliki jenis pekerjaan PNS. Jenis pekerjaan yang paling sedikit adalah dosen, guru, konsultan, staf pengajar, akupunturis dan belum bekerja dengan jumlah 2,22\%. Hal ini menunjukkan bahwa mayoritas responden makanan khas Bengkulu memiliki pekerjaan sebagai PNS. Dari jenis pekerjaan ini, jumlah responden berdasarkan penghasilan didapatkan bahwa 57,78\% memiliki penghasilan lebih dari Rp 2.000.000,00. Sementara itu, sebanyak 4,44\% dengan besar penghasilan antara Rp 1.000.000,00 - Rp 1.499.000,00. Dapat disimpulkan bahwa dari keseluruhan responden masing-masingnya sudah memiliki penghasilan yang mencukupi, yaitu besar sama dengan $\mathrm{Rp}$ $2.000 .000,00$.

\section{Opini tentang Kesadaran/Awarness/Need Recognition Responden Makanan Khas}

Dari beberapa pernyataan tentang opini kesadaran, disini kita dapat melihat dan mengukur sejauh mana responden konsumen mengenal dan mengingat makanan khas yang ditawarkan oleh perusahaan tersebut.

Persentase asal mengenal tertinggi dari keseluruhan responden adalah $55,56 \%$ yaitu sebanyak 25 orang dengan asal mengenal makanan khas Bengkulu dari teman/tetangga. Untuk masing-masing sampel, persentase asal mengenal tertinggi adalah dari teman/tetangga dengan persentase $46,47 \%, 73,33 \%$ dan 
$46,67 \%$. Ini menyatakan bahwa pada umumnya responden mengenal makanan khas Bengkulu dari teman atau tetangga.

Tabel 1. Karakteristik Responden Makanan Khas Bengkulu

\begin{tabular}{|c|c|c|c|c|c|c|c|c|c|}
\hline \multirow{2}{*}{ No } & \multirow{2}{*}{$\begin{array}{c}\text { Karakteristik } \\
\text { Responden }\end{array}$} & \multirow{2}{*}{ Jumlah } & \multirow{2}{*}{$\%$} & \multicolumn{2}{|c|}{ Cita Rasa } & \multicolumn{2}{|c|}{ Kueku Yovita } & \multicolumn{2}{|c|}{ Arzel } \\
\hline & & & & Jumlah & $\%$ & Jumlah & $\%$ & Jumlah & $\%$ \\
\hline \multirow[t]{5}{*}{1} & Umur (tahun) & & & & & & & & \\
\hline & $18-27$ & 15 & 33.33 & 5 & 33.33 & 4 & 30.77 & 6 & 40.00 \\
\hline & $28-37$ & 12 & 26.67 & 4 & 26.67 & 3 & 23.08 & 5 & 33.33 \\
\hline & $38-47$ & 12 & 26.67 & 5 & 33.33 & 4 & 30.77 & 3 & 20.00 \\
\hline & $>=48$ & 6 & 13.33 & 1 & 6.67 & 2 & 15.38 & 1 & 6.67 \\
\hline \multirow[t]{8}{*}{2} & Tingkat pendidikan & & & & & & & & \\
\hline & SD & 1 & 2.22 & 0 & 0 & 0 & 0 & 1 & 6.67 \\
\hline & SMP & 0 & 0 & 0 & 0 & 0 & 0 & 0 & 0 \\
\hline & SMA/SMK/STM & 17 & 37.78 & 6 & 40 & 6 & 40 & 5 & 33.33 \\
\hline & D3 & 3 & 6.67 & 1 & 6.67 & 1 & 6.67 & 1 & 6.67 \\
\hline & S1 & 22 & 48.89 & 6 & 40 & 8 & 53.33 & 8 & 53.33 \\
\hline & S2 & 1 & 2.22 & 1 & 6.67 & 0 & 0 & 0 & 0 \\
\hline & S3 & 1 & 2.22 & 1 & 6.67 & 0 & 0 & 0 & 0 \\
\hline \multirow[t]{12}{*}{3} & Pekerjaan & & & & & & & & \\
\hline & IRT & 4 & 8.89 & 0 & 0 & 4 & 26.67 & 0 & 0.00 \\
\hline & PNS & 15 & 33.33 & 1 & 6.67 & 4 & 26.67 & 10 & 66.67 \\
\hline & Wiraswasta & 7 & 15.56 & 3 & 20 & 3 & 20 & 1 & 6.67 \\
\hline & Swasta & 8 & 17.78 & 6 & 40.00 & 1 & 6.67 & 1 & 6.67 \\
\hline & Mahasiswa & 5 & 11.11 & 1 & 6.67 & 1 & 6.67 & 3 & 20.00 \\
\hline & Dosen & 1 & 2.22 & 1 & 6.67 & 0 & 0 & 0 & 0 \\
\hline & Guru & 1 & 2.22 & 1 & 6.67 & 0 & 0 & 0 & 0 \\
\hline & Konsultan & & & & & & & & \\
\hline & pengajar & 1 & 2.22 & 0 & 0.00 & 1 & 6.67 & 0 & 0 \\
\hline & Akupunturis & 1 & 2.22 & 1 & 6.67 & 0 & 0 & 0 & 0 \\
\hline & Tidak bekerja & 1 & 2.22 & 0 & 0.00 & 1 & 6.67 & 0 & 0 \\
\hline \multirow[t]{7}{*}{4} & Penghasilan & & & & & & & & \\
\hline & $<1.000 .000$ & 13 & 28.89 & 3 & 20 & 4 & 26.67 & 4 & 26.67 \\
\hline & $1.000 .000-$ & & & & & & & & \\
\hline & 1.499 .000 & 4 & 8.89 & 2 & 13.33 & 1 & 6.67 & 1 & 6.67 \\
\hline & $1.500 .000-$ & & & & & & & & \\
\hline & 1.999 .000 & 2 & 4.44 & 0 & 0 & 1 & 6.67 & 1 & 6.67 \\
\hline & $\geq 2.000 .000$ & 26 & 57.78 & 10 & 66.67 & 9 & 60 & 9 & 60 \\
\hline
\end{tabular}

Sumber : Data primer (diolah 2012)

Opini tentang ketertarikan (Interest)/Information Search+Evaluation of Alternative konsumen makanan khas sentra oleh-oleh Bengkulu

Pada pernyataan terhadap kondisi ketertarikan, konsumen melakukan pencarian akan informasi tentang produk yang diinginkan. Persentase responed pernah mendengar/melihat iklan makanan khas oleh keseluruhan responden adalah $20 \%$, media iklannya adalah Televisi dengan persentase $15,56 \%$. Media lainnya adalah sekolah dan internet dengan persentase masing-masing 2,22\%. Persentase tidak pernah mendengar/melihat iklan makanan khas oleh keseluruhan responden adalah $80 \%$. Hal ini menunjukkan bahwa sebagian besar 
responden makanan khas Bengkulu tidak pernah mendengar/melihat iklan makanan khas.

Tabel 2. Gambaran umum responden berdasarkan pernyataan asal mengenal makanan khas Bengkulu

\begin{tabular}{|c|c|c|c|c|c|c|c|c|}
\hline \multirow{3}{*}{$\begin{array}{l}\text { Asal mengenal } \\
\text { makanan khas }\end{array}$} & \multirow{3}{*}{$\begin{array}{l}\text { Jumlah } \\
\text { (orang) }\end{array}$} & \multirow{3}{*}{$\%$} & \multicolumn{6}{|c|}{ Sampel } \\
\hline & & & \multicolumn{2}{|c|}{ Cita Rasa } & \multicolumn{2}{|c|}{ Kueku Yovita } & \multicolumn{2}{|c|}{ Arzel } \\
\hline & & & $\begin{array}{l}\begin{array}{l}\text { Jumlah } \\
\text { (orang) }\end{array} \\
\end{array}$ & $\%$ & $\begin{array}{l}\text { Jumlah } \\
\text { (orang) }\end{array}$ & $\%$ & $\begin{array}{l}\text { Jumlah } \\
\text { (orang) }\end{array}$ & $\%$ \\
\hline Teman/tetangga & 25 & 55.56 & 7 & 46.67 & 7 & 46.67 & 11 & 73.33 \\
\hline Orangtua & 3 & 6.67 & 2 & 13.33 & 2 & 13.33 & 1 & 6.67 \\
\hline Diri sendiri & 13 & 28.89 & 6 & 40 & 6 & 40 & 1 & 6.67 \\
\hline Sekolah & 1 & 2.22 & 0 & 0 & 0 & 0 & 1 & 6.67 \\
\hline Keluarga & 2 & 4.44 & 0 & 0 & 0 & 0 & 1 & 6.67 \\
\hline Internet & 1 & 2.22 & 0 & 0 & 0 & 0 & 0 & 0 \\
\hline Total & 45 & 100 & 15 & 100 & 15 & 100 & 15 & 100 \\
\hline
\end{tabular}

Sumber : Data primer (diolah 2012)

Persentase tertinggi berdasarkan pernyataan perlunya iklan makanan khas dari keseluruhan responden adalah 95,56\% yaitu sebanyak 43 orang. Hal ini menunjukkan bahwa pada umumnya responden memerlukan iklan makanan khas Bengkulu. Persentase pernyataan tidak perlunya iklan makanan khas dari keseluruhan responden adalah $2,22 \%$. Persentase pernyataan ragu-ragu dari keseluruhan responden adalah 2,22\%.

Persentase tertinggi berdasarkan pernyataan media iklan yang paling tepat dari keseluruhan responden adalah $66,67 \%$ yaitu sebanyak 30 orang dengan menggunakan media Televisi, diikuti Radio dan Koran/Majalah sebesar 20\% dan $13,33 \%$.

\section{Analytical Hierarchy Process (AHP)}

Dari pendapat delapan pakar yang diolah dengan metode Analytical Hierarchy Process (AHP) diperoleh bobot masing-masing faktor dari masingmasing bauran pemasaran. Berdasarkan tabel 4, untuk kriteria (bauran pemasaran) produk diperoleh 14 faktor (strategi). Faktor (strategi) yang diprioritaskan adalah kebersihan produk dengan bobot terbesar yaitu 0,1222. Sedangkan faktor (strategi) dengan bobot terkecil adalah penganekaragaman ukuran produk sebesar 0,0393 .

Berdasarkan Tabel 5, untuk kriteria (bauran pemasaran) harga diperoleh sembilan faktor (strategi). Faktor (strategi) yang diprioritaskan adalah value for money dengan bobot terbesar yaitu 0,2025. Sedangkan faktor (strategi) dengan bobot terkecil adalah syarat kredit untuk tiap-tiap pesanan sebesar 0,0333. 
Tabel 3. Gambaran umum responden berdasarkan pernyataan pernah/tidak pernah, perlu/tidak perlu iklan serta media iklan paling tepat untuk makanan khas

\begin{tabular}{|c|c|c|c|c|c|c|c|c|c|}
\hline \multirow{3}{*}{ No } & \multirow{3}{*}{$\begin{array}{l}\text { Pernyataan } \\
\text { responden }\end{array}$} & \multirow{3}{*}{ Jumlah } & \multirow{3}{*}{$\%$} & \multicolumn{6}{|c|}{ Sampel } \\
\hline & & & & \multicolumn{2}{|c|}{ Cita Rasa } & \multicolumn{2}{|c|}{ Kueku Yovita } & \multicolumn{2}{|c|}{ Arzel } \\
\hline & & & & Jumlah & $\%$ & Jumlah & $\%$ & Jumlah & $\%$ \\
\hline \multirow[t]{5}{*}{1} & $\begin{array}{l}\text { Mendengar/ } \\
\text { melihat iklan } \\
\text { Pernah: }\end{array}$ & & & & & & & & \\
\hline & Televisi & 7 & 15.56 & 6 & 40 & 0 & 0 & 1 & 6.67 \\
\hline & Sekolah & 1 & 2.22 & 0 & 0 & 0 & 0 & 1 & 6.67 \\
\hline & Internet & 1 & 2.22 & 0 & 0 & 1 & 6.67 & 0 & 0 \\
\hline & Tidak pernah & 36 & 80 & 9 & 60 & 14 & 93.33 & 13 & 86.67 \\
\hline \multirow[t]{3}{*}{2} & Perlu & 43 & 95.56 & 14 & 93.33 & 15 & 100 & 14 & 93.33 \\
\hline & Tidak perlu & 1 & 2.22 & 1 & 6.67 & 0 & 0 & 0 & 0 \\
\hline & Ragu-ragu & 1 & 2.22 & 0 & 0 & 0 & 0 & 1 & 6.67 \\
\hline \multirow[t]{4}{*}{3} & $\begin{array}{l}\text { Media iklan } \\
\text { paling tepat }\end{array}$ & & & & & & & & \\
\hline & Radio & 5 & 11.11 & 3 & 20.00 & 2 & 13.33 & 0 & 0.00 \\
\hline & Koran/majalah & 10 & 22.22 & 2 & 13.33 & 8 & 53.33 & 0 & 0.00 \\
\hline & Televisi & 30 & 66.67 & 10 & 66.67 & 5 & 33.33 & 15 & 100 \\
\hline
\end{tabular}

Sumber : Data primer (diolah 2012)

Tabel 4. Bobot Dan Rangking Opini Pakar Terhadap Bauran Pemasaran Produk

\begin{tabular}{lcc}
\hline \multicolumn{1}{c}{ Faktor } & Bobot & Ranking \\
\hline Kebersihan produk & 0.1222 & 1 \\
Cita rasa produk & 0.1162 & 2 \\
Kekhasan produk lokal yang berbasis bahan lokal & 0.1004 & 3 \\
Kejujuran informasi label produk & 0.0900 & 4 \\
Pelabelan & 0.0847 & 5 \\
Perancangan desain baru & 0.0770 & 6 \\
Pengomposisian bahan baku & 0.0747 & 7 \\
Kemudahan mengenal nama merek dan ciri & 0.0654 & 8 \\
Peningkatan mutu produk & 0.0504 & 9 \\
Perubahan kemasan produk & 0.0472 & 10 \\
Peningkatan inovasi & 0.0463 & 11 \\
Penambahan keragaman produk & 0.0448 & 12 \\
Product Bundling & 0.0414 & 13 \\
Penganekaragaman ukuran produk & 0.0393 & 14 \\
\hline
\end{tabular}

Sumber : Data primer (diolah 2012) 
Tabel 5. Bobot Dan Rangking Opini Pakar Terhadap Bauran Pemasaran Harga

\begin{tabular}{lcc}
\hline \multicolumn{1}{c}{ Faktor } & Bobot & Rangking \\
\hline $\begin{array}{l}\text { Value for money } \\
\text { Pelayanan dan harga yang memuaskan konsumen }\end{array}$ & 0.2025 & 1 \\
atau pelanggan & 0.1798 & 2 \\
$\begin{array}{l}\text { Pemberian potongan harga khusus } \\
\text { Harga yang mencerminkan kualitas }\end{array}$ & 0.1393 & 3 \\
Metode pembayaran & 0.1345 & 4 \\
$\begin{array}{l}\text { Pemberian potongan harga atau diskon } \\
\text { Daftar harga }\end{array}$ & 0.1013 & 5 \\
Periode pembayaran untuk tiap-tiap pemesanan & 0.0973 & 6 \\
barang & 0.0691 & 7 \\
Syarat kredit untuk tiap-tiap pesanan & 0.0430 & 8 \\
\hline
\end{tabular}

Sumber : Data primer (diolah 2012)

Tabel 6. Bobot Dan Rangking Opini Pakar Terhadap Bauran Pemasaran Promosi

\begin{tabular}{|c|c|c|}
\hline Faktor & Bobot & Rangking \\
\hline Positioning kekhasan produk lokal & 0.1539 & 1 \\
\hline Pengetahuan penjual akan produk & 0.1040 & 2 \\
\hline Penyediaan kehumasan (Public relation) & 0.0906 & 3 \\
\hline Keramahan tenaga penjual (salesforce) & 0.0836 & 4 \\
\hline Pengintensifan pelayanan konsumen & 0.0666 & 5 \\
\hline Bonus untuk perantara (sopir travel, bis wisata) & 0.0636 & 6 \\
\hline Penampilan tenaga penjual (rapi dan bersih) & 0.0606 & 7 \\
\hline $\begin{array}{l}\text { Penyebaran brosur/materi promosi ke asosiasi } \\
\text { perjalanan (bandara, travel, dll) }\end{array}$ & 0.0604 & 8 \\
\hline Promosi penjualan & 0.0601 & 9 \\
\hline Promosi melalu website & 0.0589 & 10 \\
\hline Penambahan tenaga penjualan (Personal selling) & 0.0431 & 11 \\
\hline Penambahan iklan di media & 0.0412 & 12 \\
\hline Pemberian bonus kepada konsumen & 0.0386 & 13 \\
\hline Pelaksanaan pemasaran langsung & 0.0376 & 14 \\
\hline Kerjasama dengan partai besar & 0.0373 & 15 \\
\hline
\end{tabular}

Sumber : Data primer (diolah 2012)

Berdasarkan Tabel 6, untuk kriteria (bauran pemasaran) promosi diperoleh 15 faktor (strategi). Faktor (strategi) yang diprioritaskan adalah positioning kekhasan produk lokal dengan bobot terbesar yaitu 0,1539. Sedangkan faktor (strategi) dengan bobot terkecil adalah kerjasama dengan partai besar sebesar 0,0373. Untuk kriteria (bauran pemasaran) tempat diperoleh 10 faktor (strategi). Faktor (strategi) yang diprioritaskan adalah posisi lokasi penjualan dengan bobot terbesar yaitu 0,1841. Sedangkan faktor (strategi) dengan bobot terkecil adalah perluasan lokasi penjualan sebesar 0,0517 (Tabel 7). 
Tabel 7. Bobot Dan Rangking Opini Pakar Terhadap Bauran Pemasaran Tempat

\begin{tabular}{lcc}
\hline \multicolumn{1}{c}{ Faktor } & Bobot & Rangking \\
\hline Posisi lokasi penjualan & 0.1841 & 1 \\
Tataan outlet (layout) & 0.1632 & 2 \\
Tampilan outlet & 0.1142 & 3 \\
Perluasan cakupan pasar & 0.1122 & 4 \\
Transportasi & 0.0962 & 5 \\
Penambahan sub-distributor & 0.0742 & 6 \\
Penambahan gudang persediaan & 0.0683 & 7 \\
Perbanyakan saluran pemasaran & 0.0681 & 8 \\
Perluasan jaringan & 0.0679 & 9 \\
Perluasan lokasi penjualan & 0.0517 & 10 \\
\hline
\end{tabular}

Sumber : Data primer (diolah 2012)

\section{Analisis SWOT}

Analisis SWOT dilakukan dengan menentukan faktor internal (kekuatan dan kelemahan) dan eksternal (peluang dan ancaman). Masing-masing faktor diberikan nilai bobot yang sama. Kemudian diformulasikan strategi alternatif pengembangan pemasaran makanan khas.

\section{Cita Rasa}

Faktor internal (kekuatan dan kelemahan), faktor eksternal (peluang dan ancaman), dan formulasi strategi alternatif pengembangan pemasaran makanan khas Cita Rasa dapat dilihat pada Tabel 8.

\section{Strategi S-O}

\section{Memberi insentif harga bagi konsumen}

Pemberian insentif harga bagi konsumen dapat dilakukan melalui pemberian potongan harga atau diskon dan pemberian potongan harga khusus. Kedua potongan harga ini berbeda. Pemberian potongan harga atau diskon dimaksudkan dengan adanya pengurangan harga dari besar yang harusnya dibayar oleh konsumen. Potongan harga ini dapat dilakukan untuk setiap pembelian yang terjadi. Potongan harga khusus dimaksudkan adanya pemotongan harga yang dilakukan pada saat-saat tertentu (hari besar, peringatan perayaan tertentu, peluncuran produk baru) atau memberikan potongan harga khusus pelanggan tetap dan membeli banyak.

\section{Memperluas pasar}

Cita Rasa sudah banyak dikenal oleh masyarakat. Karenanya Cita Rasa dapat memperluas cakupan pasar dengan menambah sub distributor baik di dalam atau di luar daerah, dan memperluas jaringan. Cita Rasa melakukan usahanya bukan hanya di toko sendiri, tetapi bisa dengan melakukan kerjasama 
untuk menjual produknya dengan penjual makanan dan makanan khas di tempat-tempat lainnya, baik di daerah yang sama atau di luar kota.

\section{Strategi S-T}

\section{Menjaga dan mempertahankan mutu (kualitas), cita rasa dan kekhasan produk}

Kualitas, cita rasa dan kekhasan produk lokal penting bagi usaha untuk mendukung daya saing produk. Kekhasan produk berbasis bahan lokal dan mampu menunjukkan asal daerah makanan tersebut sehingga mudah untuk mengenali daerah asalnya. Pembeli tidak hanya berasal dari daerah lokal. Karenanya, perlu menjaga kualitas dan cita rasanya agar makanan tidak cepat rusak seperti keinginan konsumen.

\section{Penataan outlet dengan memberikan tampilan yang menarik}

Outlet (layout) perlu ditata dengan baik agar enak dilihat dan menarik minat konsumen. Penataan outlet bisa dilakukan dengan menyusun berdasarkan harga, jenis makanannya, ataupun ukurannya. Outlet akan mempermudah pembeli dalam membeli produk. Di samping itu, fasilitas yang dimiliki juga harus diletakkan pada tempat yang sesuai sehingga tidak membuat outlet menjadi tidak enak dilihat.

\section{Kueku Yovita}

Faktor internal (kekuatan dan kelemahan), faktor eksternal (peluang dan ancaman), dan formulasi strategi alternatif pengembangan pemasaran makanan khas Kueku Yovita dapat dilihat pada Tabel 9.

\section{Strategi S-O}

\section{Meningkatkan kegiatan promosi dan periklanan}

Kegiatan promosi dan periklanan dilakukan dengan menambah iklan di media, promosi melalui website, bonus untuk perantara (sopir travel, bis wisata), dan menyebarkan brosur promosi ke asosiasi perjalanan (bandara, travel, dll). 100\% Konsumen Kueku Yovita menyatakan bahwa iklan makanan khas perlu dilakukan dengan media iklan yang paling tepat adalah Televisi $(100 \%)$. Promosi melalui website dilakukan dengan membuat Blog pribadi atau melalui account Facebook.

Bonus untuk perantara dilakukan untuk menarik minat perantara membawa calon pembeli ke lokasi penjualan. Begitu juga dengan penyebaran bonus ke asosiasi perjalanan. Kegiatan promosi ini bertujuan untuk mengenalkan produk dan menarik calon pembeli yang berasal dari luar daerah. 
Tabel 8. Formulasi Strategi Alternatif Pengembangan Pemasaran Makanan Khas Cita Rasa

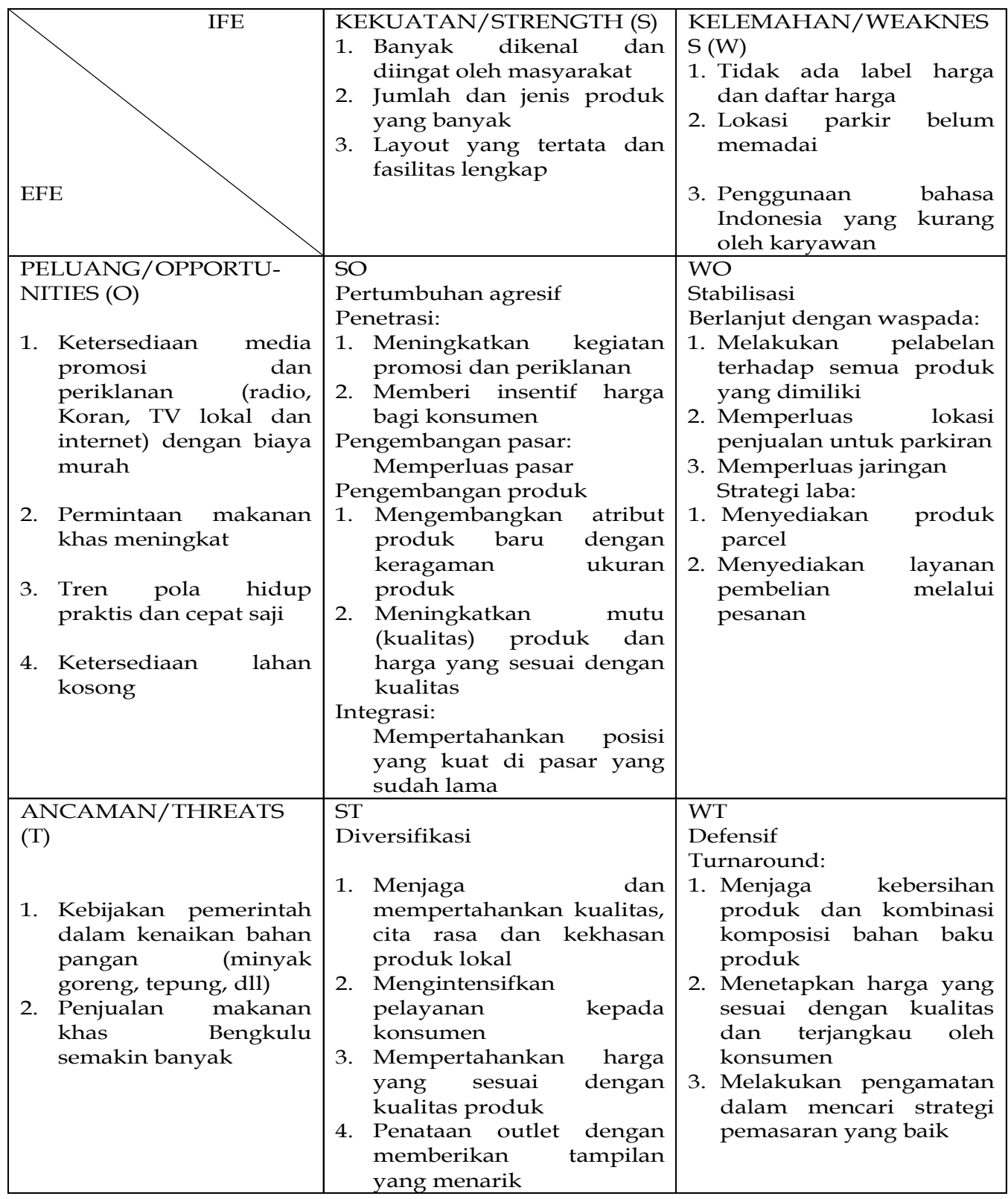

Sumber : Data primer (diolah 2012)

\section{Memberi insentif harga bagi konsumen}

Pemberian insentif harga bagi konsumen dapat dilakukan melalui pemberian potongan harga atau diskon dan pemberian potongan harga khusus. Kedua potongan harga ini berbeda. Pemberian potongan harga atau diskon dimaksudkan dengan adanya pengurangan harga dari besar yang harusnya dibayar oleh konsumen. Potongan harga ini dapat dilakukan untuk setiap 
pembelian yang terjadi. Potongan harga khusus dimaksudkan adanya pemotongan harga yang dilakukan pada saat-saat tertentu (hari besar, peringatan perayaan tertentu, peluncuran produk baru) atau memberikan potongan harga khusus pelanggan tetap dan membeli banyak.

\section{Memperluas pasar}

Kueku Yovita sudah banyak dikenal oleh masyarakat. Karenanya Kueku Yovita dapat memperluas cakupan pasar dengan menambah sub distributor baik di dalam maupundi luar daerah, serta memperluas jaringan. Kueku Yovita melakukan usahanya bukan hanya di toko sendiri, tetapi bisa dengan melakukan kerjasama menjual produknya dengan penjual makanan dan makanan khas di tempat-tempat lainnya, baik di daerah yang sama maupun di luar kota.

\section{Strategi S-T}

\section{Penataan outlet dengan memberikan tampilan yang menarik}

Outlet (layout) perlu ditata dengan baik agar enak dilihat dan menarik minat konsumen. Penataan outlet bisa dilakukan dengan menyesuaiakan berdasarkan harga, jenis makanannya, ataupun ukurannya. Outlet akan mempermudah pembeli dalam membeli produk. Di samping itu, fasilitas yang dimiliki juga harus diletakkan pada tempat yang sesuai sehingga tidak membuat outlet menjadi tidak enak dilihat.

\section{Arzel}

Faktor internal (kekuatan dan kelemahan), faktor eksternal (peluang dan ancaman), dan formulasi strategi alternatif pengembangan pemasaran makanan khas Arzel dapat dilihat pada Tabel 10.

\section{Strategi S-O}

\section{Meningkatkan kegiatan promosi dan periklanan}

Kegiatan promosi dan periklanan dilakukan dengan menambah iklan di media, promosi melalui website, bonus untuk perantara (sopir travel, bis wisata), dan menyebarkan brosur promosi ke asosiasi perjalanan (bandara, travel, dll). 93,33\% Konsumen Arzel menyatakan bahwa iklan makanan khas perlu dilakukan dengan media iklan yang paling tepat adalah Koran/Majalah $(53,33 \%)$. Promosi melalui website dilakukan dengan membuat Blog pribadi atau melalui account Facebook.

Bonus untuk perantara dilakukan untuk menarik minat perantara membawa calon pembeli ke lokasi penjualan. Begitu juga dengan penyebaran bonus ke asosiasi perjalanan. Kegiatan promosi ini bertujuan untuk mengenalkan produk dan menarik calon pembeli yang berasal dari luar daerah. 
Tabel 9. Formulasi Strategi Alternatif Pengembangan Pemasaran Makanan Khas Kueku Yovita

\begin{tabular}{|c|c|c|}
\hline EFE & $\begin{array}{l}\text { KEKUATAN/STRENGTH } \\
\text { (S) } \\
\text { 1. Banyak dikenal dan } \\
\text { diingat oleh masyarakat } \\
\text { 2. Kemasan lebih aman, } \\
\text { berkualitas, bersih dan } \\
\text { enak } \\
\text { 3. Hubungan baik dengan } \\
\text { pemasok dan pelanggan }\end{array}$ & $\begin{array}{l}\text { KELEMAHAN/WEAKNESS } \\
\text { (W) } \\
\text { 1. Jarang mengikuti pameran } \\
\text { baik lokal maupun luar } \\
\text { kota } \\
\text { 2. Jumlah dan jenis produk } \\
\text { yang lebih sedikit }\end{array}$ \\
\hline $\begin{array}{l}\text { PELUANG/OPPORTU- } \\
\text { NITIES (O) } \\
\text { 1. Ketersediaan media } \\
\text { promosi dan } \\
\text { periklanan (Koran dan } \\
\text { TV lokal dengan } \\
\text { biaya murah } \\
\text { 2. Permintaan makanan } \\
\text { khas meningkat } \\
\text { 3r. Tren pola hidup } \\
\text { praktis dan cepat saji }\end{array}$ & $\begin{array}{l}\text { SO } \\
\text { Pertumbuhan agresif } \\
\text { Penetrasi: } \\
\text { 1. Meningkatkan kegiatan } \\
\text { promosi dan periklanan } \\
\text { 2. Memberi insentif harga } \\
\text { bagi konsumen } \\
\text { Pengembangan pasar: } \\
\text { Memperluas pasar } \\
\text { Pengembangan produk: } \\
\text { 1. Meningkatkan mutu } \\
\text { (kualitas) produk dan } \\
\text { harga yang sesuai dengan } \\
\text { kualitas atribut } \\
\text { 2. Mengembangkan aru dengan } \\
\text { produk baru } \\
\text { keragaman ukuran produk } \\
\text { Integrasi: } \\
\text { Mempertahankan posisi } \\
\text { yang kuat di pasar yang } \\
\text { sudah lama }\end{array}$ & $\begin{array}{l}\text { WO } \\
\text { Stabilisasi } \\
\text { Strategi laba: } \\
\quad \text { Menyediakan } \\
\text { parcel produk } \\
\text { Berlanjut dengan waspada: } \\
\text { 1. Memperluas jaringan } \\
\text { 2. Melakukan perancangan } \\
\quad \text { desain baru }\end{array}$ \\
\hline $\begin{array}{l}\text { ANCAMAN/THREATS } \\
\text { (T) } \\
\text { 1. Kebijakan pemerintah } \\
\text { dalam kenaikan bahan } \\
\text { pangan (minyak } \\
\text { goreng, tepung, dll) } \\
\text { 2. Penjualan makanan } \\
\text { khas Bengkulu } \\
\text { semakin banyak }\end{array}$ & $\begin{array}{l}\text { ST } \\
\text { Diversikasi: } \\
\text { 1. Menjaga hubungan yang } \\
\text { baik dengan pemasok } \\
\text { dan pelanggan } \\
\text { 2. Menjaga } \\
\text { mempertahankan dan } \\
\text { keunggulan kemasan, } \\
\text { kualitas, kebersihan, dan } \\
\text { cita rasa } \\
\text { 3. Mengintensifkan } \\
\text { pelayanan } \\
\text { konsumen kepada } \\
\text { 4. Mempertahankan harga } \\
\text { yang sesuai dengan } \\
\text { kualitas produk } \\
\text { 5enataan outlet dengan } \\
\text { memberikan tampilan } \\
\text { yang menarik }\end{array}$ & $\begin{array}{l}\text { WT } \\
\text { Defensif } \\
\text { Turnaround: } \\
\text { 1. Melakukan promosi } \\
\text { penjualan dengan nama } \\
\text { merek dan ciri yang } \\
\text { mudah dikenal } \\
\text { 2. Menjaga kebersihan } \\
\text { produk dan kombinasi } \\
\text { komposisi bahan baku } \\
\text { produk harga yang } \\
\text { 3. Menetapkan harga } \\
\text { sesuai dengan kualitas dan } \\
\text { terjangkau oleh konsumen } \\
\text { 4. Melakukan pengamatan } \\
\text { dalam mencari strategi } \\
\text { pemasaran yang baik }\end{array}$ \\
\hline
\end{tabular}

Sumber : Data primer (diolah 2012) 


\section{Memberi insentif harga bagi konsumen}

Pemberian insentif harga bagi konsumen dapat dilakukan melalui pemberian potongan harga atau diskon dan pemberian potongan harga khusus. Kedua potongan harga ini berbeda. Pemberian potongan harga atau diskon dimaksudkan dengan adanya pengurangan harga dari besar yang harusnya dibayar oleh konsumen. Potongan harga ini dapat dilakukan untuk setiap pembelian yang terjadi. Potongan harga khusus dimaksudkan adanya pemotongan harga yang dilakukan pada saat-saat tertentu (hari besar, peringatan perayaan tertentu, peluncuran produk baru) atau memberikan potongan harga khusus pelanggan tetap dan membeli banyak.

\section{Memperluas pasar}

Arzel sudah banyak dikenal oleh masyarakat. Karenanya Arzel dapat memperluas cakupan pasar dengan menambah sub distributor baik di dalam atau di luar daerah, dan memperluas jaringan. Arzel melakukan usahanya bukan hanya di toko sendiri, tetapi bisa dengan melakukan kerjasama untuk menjual produknya dengan penjual makanan dan makanan khas di tempattempat lainnya, baik di daerah yang sama atau di luar kota.

\section{Strategi S-T}

\section{Meningkatkan mutu (kualitas), kebersihan, dan cita rasa produk}

Mutu (kualitas), kebersihan, dan cita rasa produk penting bagi usaha untuk mendukung daya saing produk. Pembeli tidak hanya berasal dari daerah lokal. Karenanya, perlu menjaga kualitas dan cita rasanya agar makanan tidak cepat rusak seperti keinginan konsumen.

\section{Penataan outlet dengan memberikan tampilan yang menarik}

Outlet (layout) perlu ditata dengan baik agar enak dilihat dan menarik minat konsumen. Penataan outlet bisa dilakukan dengan menyesuaiakan berdasarkan harga, jenis makanannya, ataupun ukurannya. Outlet akan mempermudah pembeli dalam membeli produk. Di samping itu, fasilitas yang dimiliki juga harus diletakkan pada tempat yang sesuai sehingga tidak membuat outlet menjadi tidak enak dilihat. 
Tabel 10. Formulasi Strategi Alternatif Pengembangan Pemasaran Makanan Khas Arzel

\begin{tabular}{|c|c|c|}
\hline IFE & $\begin{array}{l}\text { KEKUATAN/STRENGTH } \\
\text { (S) } \\
\text { 1. Banyak dikenal dan } \\
\text { diingat oleh masyarakat } \\
\text { 2. Hubungan baik dengan } \\
\text { pemasok dan pelanggan } \\
\text { 3. Harga murah dan } \\
\text { berkualitas }\end{array}$ & $\begin{array}{l}\text { KELEMAHAN/WEAKNESS } \\
\text { (W) } \\
\text { 1. Jarang mengikuti pameran } \\
\text { baik lokal maupun luar } \\
\text { kota } \\
\text { 2. Jumlah dan jenis produk } \\
\text { yang lebih sedikit }\end{array}$ \\
\hline $\begin{array}{l}\text { PELUANG/OPPORTU- } \\
\text { NITIES (O) } \\
\text { 1. } \begin{array}{l}\text { Ketersediaan media } \\
\text { promosi dan } \\
\text { periklanan }\end{array} \\
\begin{array}{l}\text { Koran, TV lokal dan } \\
\text { internet) dengan }\end{array} \\
\text { biaya murah } \\
\text { 2. } \begin{array}{l}\text { Permintaan makanan } \\
\text { khas meningkat }\end{array} \\
\text { 3. } \begin{array}{l}\text { Tren pola hidup } \\
\text { praktis dan cepat saji }\end{array}\end{array}$ & $\begin{array}{l}\text { SO } \\
\text { Pertumbuhan agresif } \\
\text { Penetrasi: } \\
\text { 1. Meningkatkan kegiatan } \\
\text { promosi dan periklanan } \\
\text { 2. Memberi insentif harga } \\
\text { bagi konsumen } \\
\text { Pengembangan pasar: } \\
\text { Memperluas pasar } \\
\text { Pengembangan produk: } \\
\text { 1. Meningkatkan putu } \\
\text { (kualitas) produk dan } \\
\text { harga yang sesuai dengan } \\
\text { kualitas pelabelan dan } \\
\text { 2. Melakukan pelabadap } \\
\text { pengemasan terhad yang } \\
\text { semua produk } \\
\text { dimiliki Integrasi: } \\
\text { Mempertahankan posisi } \\
\text { yang kuat di pasar yang } \\
\text { sudah lama }\end{array}$ & $\begin{array}{l}\text { WO } \\
\text { Stabilisasi } \\
\text { Strategi laba: } \\
\quad \text { Menyediakan produk parcel } \\
\text { Berlanjut dengan waspada: } \\
\text { 1. Memperluas jaringan } \\
\text { 2. Melakukan perancangan } \\
\text { desain baru }\end{array}$ \\
\hline $\begin{array}{l}\text { 1. } \begin{array}{l}\text { Kebijakan pemerintah } \\
\text { dalam } \\
\text { bahan } \\
\text { (minyak }\end{array} \\
\begin{array}{l}\text { kenaikan } \\
\text { pangan } \\
\text { teporeng, dll) }\end{array} \\
\text { 2. } \begin{array}{l}\text { Penjualan } \\
\text { khas makanan } \\
\text { semakin banyak }\end{array}\end{array}$ & $\begin{array}{l}\text { ST } \\
\text { Diversifikasi: } \\
\text { 1. Menjaga hubungan yang } \\
\text { baik dengan pemasok dan } \\
\text { pelanggan } \\
\text { 2. Meningkatkan mutu } \\
\text { (kualitas), kebersihan, dan } \\
\text { cita rasa produk } \\
\text { 3. Mengintensifkan } \\
\text { pelayanan } \\
\text { konsumen kepada } \\
\text { 4. Mempertahankan harga } \\
\text { yang sesuai dengan } \\
\text { kualitas produk } \\
\text { 5. Penataan outlet dengan } \\
\text { memberikan tampilan } \\
\text { yang menarik }\end{array}$ & $\begin{array}{l}\text { WT } \\
\text { Defensif } \\
\text { Turnaround: } \\
\text { 1. Melakukan promosi } \\
\text { penjualan dengan nama } \\
\text { merek dan ciri yang mudah } \\
\text { dikenal } \\
\text { 2. Menjaga kebersihan produk } \\
\text { dan kombinasi komposisi } \\
\text { bahan baku produk } \\
\text { 3. Menetapkan harga yang } \\
\text { sesuai dengan kualitas dan } \\
\text { terjangkau oleh konsumen } \\
\text { 4. Melakukan pengamatan } \\
\text { dalam mencari strategi } \\
\text { pemasaran yang baik }\end{array}$ \\
\hline
\end{tabular}

Sumber : Data primer (diolah 2012)

\section{SIMPULAN DAN SARAN}

Kekuatan internal Cita Rasa meliputi : (1) banyak dikenal dan diingat oleh masyarakat, (2) jumlah dan jenis produk yang banyak, dan (3) layout yang tertata dan fasilitas lengkap. Kelemahan internal Cita Rasa meliputi : (1) tidak ada label harga dan daftar harga, (2) lokasi parkir belum memadai, dan (3) penggunaan bahasa Indonesia yang kurang oleh karyawan. Peluang eksternal 
Cita Rasa meliputi : (1) ketersediaan media promosi dan periklanan (radio, koran, TV lokal dan internet) dengan biaya murah, (2) permintaan makanan khas meningkat, (3) tren pola hidup praktis dan cepat saji, dan (4) ketersediaan lahan kosong. Ancaman eksternal Cita Rasa meliputi : (1) Kebijakan pemerintah dalam kenaikan bahan pangan (minyak goreng, tepung, dll) dan (2) Penjualan makanan khas Bengkulu semakin banyak.

Kekuatan internal Kueku Yovita meliputi : (1) banyak dikenal dan diingat oleh masyarakat, (2) kemasan lebih aman, berkualitas, bersih dan enak, (3) hubungan baik dengan pemasok dan pelanggan. Kelemahan internal Kueku Yovita meliputi : (1) jarang mengikuti pameran dan (2) jumlah dan jenis produk yang lebih sedikit. Peluang eksternal Kueku Yovita meliputi : (1) ketersediaan media promosi dan periklanan (radio, koran, TV lokal dan internet) dengan biaya murah, (2) permintaan makanan khas meningkat, (3) tren pola hidup praktis dan cepat saji. Ancaman eksternal Kueku Yovita meliputi : (1) Kebijakan pemerintah dalam kenaikan bahan pangan (minyak goreng, tepung, dll) dan (2) Penjualan makanan khas Bengkulu semakin banyak.

Kekuatan internal Arzel meliputi : (1) banyak dikenal dan diingat oleh masyarakat, (2) hubungan baik dengan pemasok dan pelanggan, dan (3) harga murah dan berkualitas. Kelemahan internal Arzel meliputi : (1) jarang mengikuti pameran dan (2) jumlah dan jenis produk yang lebih sedikit. Peluang eksternal Arzel meliputi : (1) ketersediaan media promosi dan periklanan (radio, koran, TV lokal dan internet) dengan biaya murah, (2) permintaan makanan khas meningkat, (3) tren pola hidup praktis dan cepat saji. Ancaman eksternal Arzel meliputi : (1) Kebijakan pemerintah dalam kenaikan bahan pangan (minyak goreng, tepung, dll) dan (2) Penjualan makanan khas Bengkulu semakin banyak.

Perhitungan dengan metode Analytical Hierarchy Process (AHP) menghasilkan bobot dan ranking faktor dari masing-masing bauran pemasaran. Faktor dengan bobot tertinggi dan terendah untuk bauran pemasaran produk adalah kebersihan produk $(0,1222)$ dan keragaman ukuran produk $(0,0393)$. Faktor dengan bobot tertinggi dan terendah untuk bauran pemasaran harga adalah value for money $(0,2025)$ dan syarat kredit untuk tiap-tiap pesanan $(0,0333)$. Faktor dengan bobot tertinggi dan terendah untuk bauran pemasaran promosi adalah positioning kekhasan produk lokal $(0,1539)$ dan mengikuti partai besar $(0,0373)$. Faktor dengan bobot tertinggi dan terendah untuk bauran pemasaran tempat adalah posisi lokasi penjualan $(0,1841)$ dan memperluas lokasi penjualan $(0,0517)$.

Strategi pengembangan pemasaran Cita Rasa meliputi : (1) memberi insentif harga bagi konsumen, (2) memperluas pasar, (3) menjaga dan mempertahankan kualitas, cita rasa dan kekhasan produk, dan (4) penataan outlet dengan memberikan tampilan yang menarik. Strategi pengembangan pemasaran Kueku Yovita meliputi : (1) meningkatkan kegiatan promosi dan periklanan, (2) memberi insentif harga bagi konsumen, (3) memperluas pasar, dan (4) penataan outlet dengan memberikan tampilan yang menarik. Strategi pengembangan pemasaran Arzel meliputi : (1) meningkatkan kegiatan promosi dan periklanan, (2) memberi insentif harga bagi konsumen, (3) memperluas 
pasar, (4) meningkatkan mutu (kualitas), kebersihan dan cita rasa produk, serta (5) penataan outlet dengan memberikan tampilan yang menarik.

Strategi pengembangan pemasaran sentra oleh-oleh sebaiknya dilakukan dengan tetap memperhatikan lingkungan internal dan eksternal masing-masing usaha untuk keberlanjutan usaha yang semakin baik ke depannya. Sentra Oleholeh Cita Rasa dan Kueku Yovita lebih menekankan strategi terhadap bauran tempat, sedangkan unit usaha Sentra Oleh-oleh Arzel pada bauran pemasaran produk.

\section{DAFTAR PUSTAKA}

Afiah, Nunuy Nur. 2009. Peran Kewirausahaan dalam Memperkuat UKM Indonesia Menghadapi Krisis Finansial Global. Working Paper in Accounting and Finance. ppa.fe.unpad.ac.id/uploads/file/wp-acc01.pdf (Diakses tanggal 7 Maret 2012)

Arikunto, S. 1996. Prosedur Penelitian Suatu Pendekatan Praktis. Bina Aksara, Jakarta

Assauri, Sofjan. 2011. Manajemen Pemasaran. Rajawali Press, Jakarta.

Kuncoro, Mudrajad. 2000. Usaha Kecil di Indonesia : Profil, Masalah dan Strategi Pemberdayaan.

http://website.mudrajad.com/sites/

default/files/softcopies/Usaha\%20Kecil\%20di\%20Indonesia\%20-

\%20Profil,\%20Masalah,\%20dan\%20Strategi\%20Pemberdayaan.pdf

(Diakses tanggal 7 Maret 2012)

Kamaluddin. 2010. Strategi Pemasaran Agribisnis.

http:/ / kamaluddin86.blogspot.com/2010/01/strategi-pemasaranagribisnis20.html (diakses pada 20 Desember 2011)

Marimin. 2004. Teknik dan Aplikasi : Pengambilan Keputusan Kriteria Majemuk. Gramedia Widiasarana Indonesia, Jakarta.

Nangoi, Ronald. 1996. Menentukan Strategi Pemasaran dalam Menghadapi Persaingan. Rajawali Press, Jakarta.

Nazir, M. 1987. Metode Penelitian. Ghalia Indonesia, Jakarta.

Rohim, Abd. 2008. Analisis Strategi Pemasaran Melalui Pendekatan SWOT (Studi pada PT. Pujangga Luhur Jombang). Jurnal Ekonomi Manajemen dan Bisnis (EMAS), 2(1): 1 - 10, April, 2008 